\title{
ANATOMICAL PREDICTIONS OF DEVELOPMENT OF RHINOSINUSITIS AND ITS COMPLICATIONS
}

\author{
Alekseeva $V$. \\ Kharkiv National Medical University, Ukraine \\ https://doi.org/10.35339/ic.7.3.125-130
}

\begin{abstract}
Background. The anatomical structure of the paranasal sinuses of a person predetermines the risk of development, diversity of presentation, possibility of complications and features of surgical treatment of rhinosinusitis. Objective: of our study was to determine the thickness and density of the walls of the maxillary and frontal sinuses, which are potentially dangerous in terms of the development of complications. Materials and methods: Our study involved 121 subjects without any ENT diseases, who underwent SCT examination due to the reasons that were not related to abnormalities of ENT organs. Thickness and density in the region of the lower (orbital) wall and posterior (cerebral) wall of the frontal sinus were calculated.

Results and Discussion. The maximum density was characteristic of the lower wall of the frontal sinus under physiological conditions and appeared $107.96 \pm 201.64 \mathrm{Hu}$, the minimum for the lower wall was $-29.98 \pm 208.54 \mathrm{Hu}$. The thickness of the bone tissue in the frontal sinus was $4.05 \pm 2.04 \mathrm{~mm}$. Conclusion. The minimum density and thickness of the lower and posterior walls of the frontal sinus and upper and lower walls of the maxillary sinus was established under physiological conditions. The density of the posterior wall was found to be $25.4 \%$ lower than the density of the lower wall, and the thickness $22.2 \%$ lower.

Key words: Frontal sinus, Maxillary sinus, Spiral computed tomography, Bone density, Bone thickness.
\end{abstract}

\section{Introduction}

The anatomical structure of the paranasal sinuses (PNSs) of a person predetermines the risk of development, diversity of presentation, possibility of complications and features of surgical treatment of their inflammation, rhinosinusitis [1-3].

The maxillary sinus is more involved in inflammatory processes than other PNSs [4], which is due to the peculiarities of its anatomical and topographic location, the largest volume, location of the anastomosis above the bottom of the sinus, proximity of teeth. Therefore, maxillary sinusitis is one of the most common forms of rhinosinusitis [5]. This fact is of great interest in the study of the anatomical structure of this area. The most significant in terms of complications is the upper wall, which is at the same time the lower

Corresponding Author:

Victoriia V. Alekseeva, Assistant

of the Department of Histology, Cytology,

Embryology, Kharkiv National Medical University,

E-mail: vik13052130@i.ua wall of the orbit. Impairment of the integrity of this wall can result in the spread of purulentinflammatory processes into the orbit. Equally important is the lower wall of the maxillary sinus - a potentially dangerous area for the development of odontogenic maxillary sinusitis.

The anatomical structure of the frontal sinus is also of great importance for development of inflammatory pathological processes [6] and their complications with spread to the neighboring organs and tissues (orbital phlegmon, brain abscess, meningitis). Pathological processes occurring in the frontal sinus due to its topographic and anatomical relationships with nearby structures most often lead to complications. Chronic frontal sinusitis has the greatest specific weight for their occurrence, because they are associated with bone changes in the sinus walls, such as bone demineralization, disappearance of trabeculae, cortical destruction, and focal sclerosis. These changes are manifested as a decrease in bone density, as proven by Dong et al [7]. In addition to density, destructive processes often lead to a change in the thickness of the 
Global Osteitis Scoring Scale, in which the degree of destruction is associated with a decrease in bone thickness [8]. These changes can correlate with the severity of the disease, which must be taken into account when planning surgery for the maxillary sinuses and predicting possible complications.

\section{Purposes, subjects and methods:}

\subsection{Purpose}

Given all of the above, the aim of our study was to determine the thickness and density of the walls of the maxillary and frontal sinuses, which are potentially dangerous in terms of the development of complications.

\subsection{Subjects \& Methods}

This study is a part of research work "Optimization of early diagnosis, prevention and treatment of oral tissue diseases with smoking addiction", No. 0120U102057, Kharkiv National Medical University, and is funded by Ministry of Health of Ukraine.

Our study involved 121 subjects without any ENT diseases, who underwent SCT examination due to reasons that were not related to abnormalities of ENT organs (suspected stroke, etc.). The patients were selected with the same distribution by gender and age. The age of the subjects was from 25 to 65 years (see Fig. 1).

The study was performed using spiral computed tomography (SCT) findings, a simple, informative, and generally accessible intravital method for determining bone density, which helps

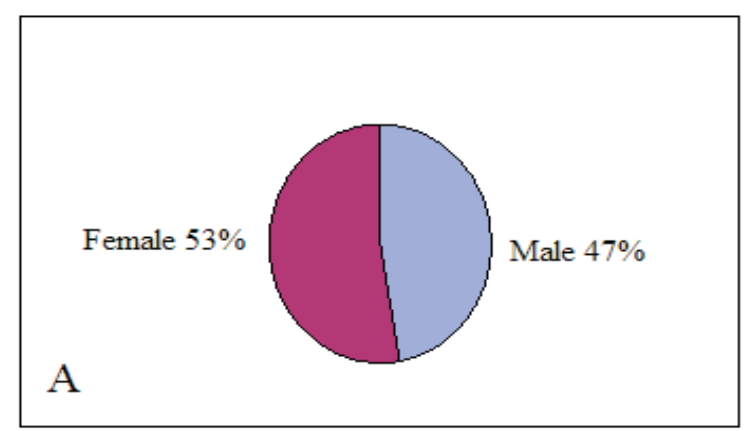

organism morphology and function [10] with nonobligatory linear-feedback connection [11].

SCT examination makes it possible to identify the sizes and shape of the frontal and maxillary sinuses, which differ in great individual and agerelated variability [12].

All patients gave voluntary consent to participate in the studies and were examined by an otolaryngologist. After the SCT examination, the radiologist's conclusion was obtained. To evaluate the bone density by SCT, Hounsfield scale was used, considering that according to $\mathrm{M}$. Hofer, modern devices can cover 4096 shades of gray scale, which represent different density levels in Hounsfield units (HU) (the density of water is taken as $0 \mathrm{HU}$, and air as $1000 \mathrm{HU}$ ) [13].

We studied the indicators of the minimum density in all sections presented. The calculation of the thickness was carried out in the thinnest section of the wall (see Fig. 2).

Axial sections and coronary reconstructions were investigated. The thickness and density in the region of the lower (orbital) wall were calculated as the most significant in terms of intraorbital complications development [14], the posterior (cerebral) wall of the frontal sinus was studied, since it is of the greatest importance for performing endoscopic interventions [15].

The obtained digital data were statistically processed using Student-Fisher method, the average value for each variation series $(\mathrm{X})$, standard deviation, and the mean error $(\mathrm{m})$ were determined.

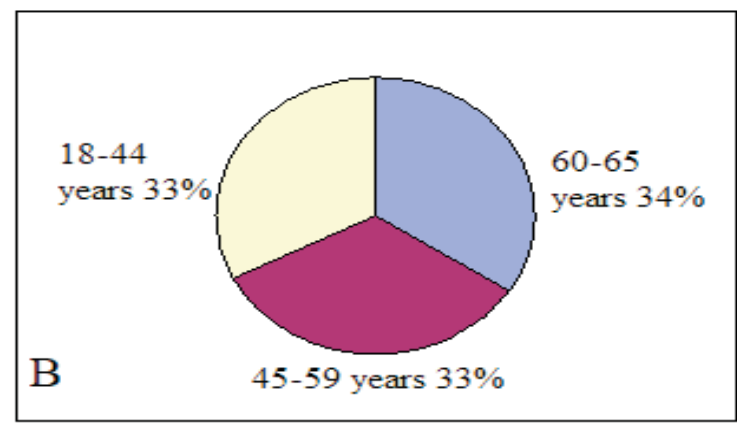

to identify structural features, relative position of PNSs, determine the microarchitectonics of bone wall tissue and determine possible prerequisites for the development of rhinosinusitis complications.

Adherence to the principle of non-invasive investigation is so important that often the study of processes in the human body is replaced by modeling or setting up an experiment [9].

Noninvasive detection of internal intravital peculiarities is extremely important for human
Statistical processing was carried out on a personal computer using Microsoft Office Excel 2010 software (USA). The results were considered statistically significant at $\mathrm{p}<0.05$.

The article complies with the requirements of the Declaration of Helsinki. The study was approved by the Bioethics Committee of Kharkiv National Medical University.

\section{Conflict of interests}

The authors of the article declare no conflict of interest. 

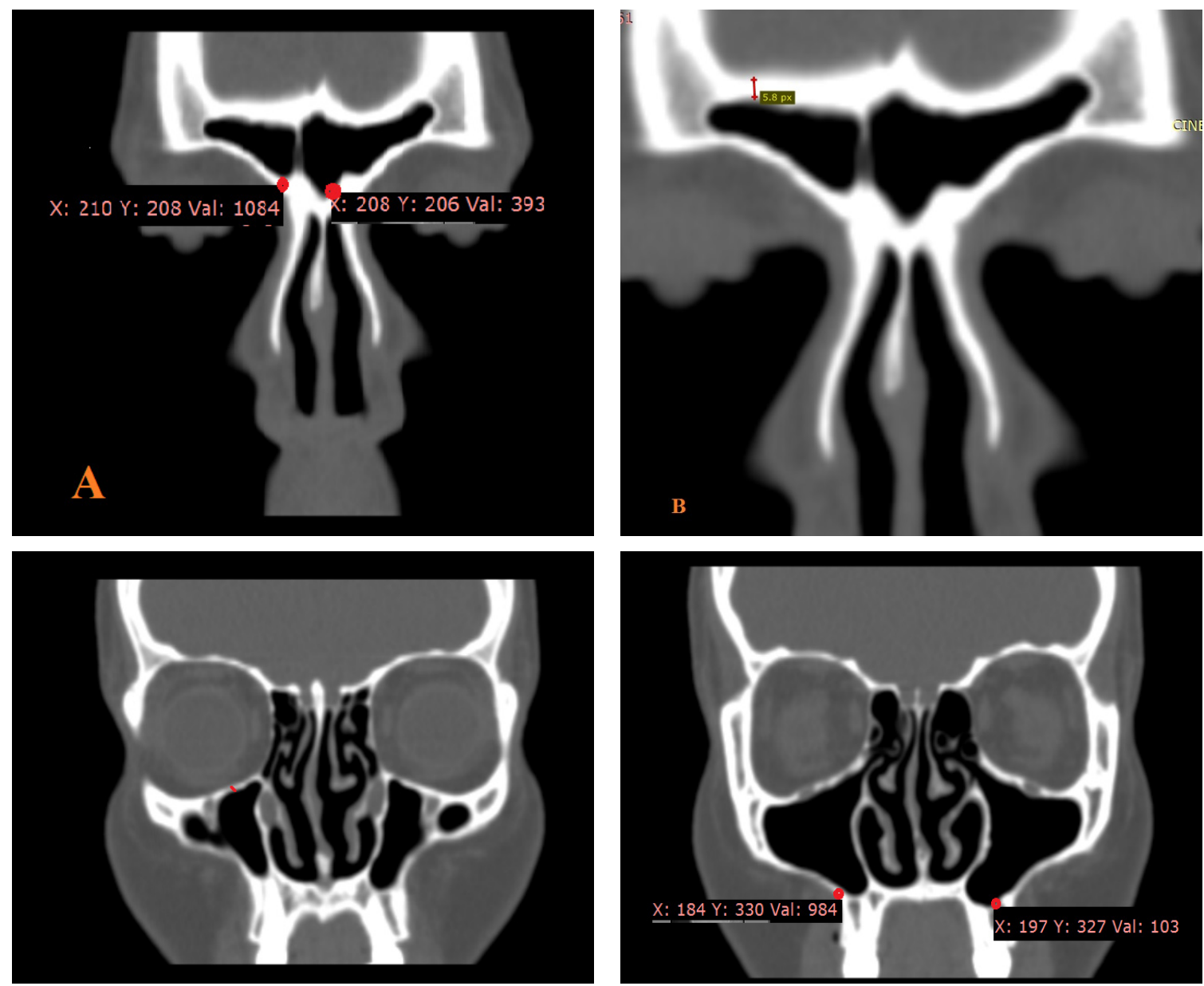

Fig. 2. Example of measuring the density (A) and bone thickness (B) of the frontal sinus and maxillary sinus. SCT, coronary reconstruction

Table 1

Density (Hu) and thickness (mm) of the lower and posterior walls of the frontal sinus

\begin{tabular}{|l|c|c|c|c|}
\hline \multirow{2}{*}{ Indicator } & \multicolumn{2}{|c|}{ Lower wall } & \multicolumn{2}{c|}{ Posterior wall } \\
\cline { 2 - 5 } & Thickness & Density & Thickness & Density \\
\hline $\mathrm{M}$ & 4.05 & 107.96 & 1.0006 & 27.42 \\
\hline$\sigma$ & 2.04 & 201.64 & 0.538 & 168.76 \\
\hline
\end{tabular}

Table 2

Density (Hu) and thickness $(\mathrm{mm})$ of the upper and lower walls of the maxillary sinus

\begin{tabular}{|l|c|c|c|c|}
\hline \multirow{2}{*}{ Indicator } & \multicolumn{2}{|c|}{ Upper wall } & \multicolumn{2}{c|}{ Lower wall } \\
\cline { 2 - 5 } & Width & Density & Width & Density \\
\hline $\mathrm{M}$ & 2.03 & 33.21 & 4.47 & -29.98 \\
\hline$\sigma$ & 1.01 & 109.72 & 2.11 & 208.54 \\
\hline
\end{tabular}

\section{Results \& Discussion}

The results of determining the thickness and density of bone tissue $\mathrm{(Hu}$ ) in SCT study using the Hounsfield scale are presented in Tables 1-2.

During the study, the minimum thickness and density of the posterior (see Table 2) and lower (see Table 1) walls of the frontal and maxillary sinus were determined in physiological conditions.
The study has shown that the maximum density is characteristic of the lower wall of the frontal sinus under physiological conditions and is 107.96 $\pm 201.64 \mathrm{Hu}$, the minimum for the lower wall is $29.98 \pm 208.54 \mathrm{Hu}$. The thickness of the bone tissue in the frontal sinus is $4.05 \pm 2.04 \mathrm{~mm}$.

The posterior wall was shown to be much thinner than the lower one, creating the conditions 

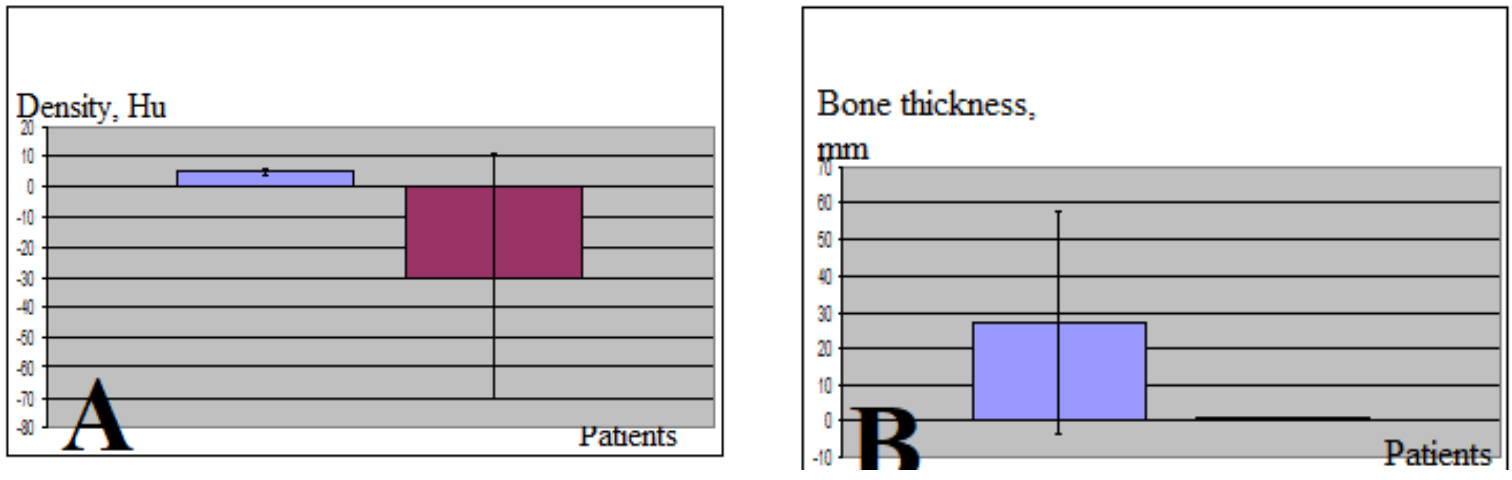

Fig. 3 Chart of average values with confidence intervals of thickness and density of the lower (A) and posterior (B) walls in purulent-polypous frontal sinusitis

for the spread of purulent-inflammatory processes with the development of intracranial complications. The thickness of the lower wall $(4.05 \pm 2.04 \mathrm{~mm})$ was found to be $22.2 \%$ higher than the posterior one $(1.006 \pm 0.538 \mathrm{~mm})$ under physiological conditions. Based on this, it can be assumed that chronic frontal sinusitis creates more favorable conditions for the spread of the inflammatory process intracranially than intraorbitally. In addition, the likelihood of complications increases due to the lower density in the region of the posterior wall than the lower one. Thus, the density of the posterior wall even under physiological conditions $(27.42 \pm 168.76 \mathrm{Hu})$ is $25.4 \%$ lower than that of the lower one $(107.96 \pm 201.64 \mathrm{Hu})$. In maxillary sinuses, on the contrary, intraorbital complications may prevail over intracranial complications [16].

The minimum thickness of the lower wall of the maxillary sinus was also found to be the thickest among all the studied walls $(4.47 \pm 2.11 \mathrm{~mm})$. However, it is interesting that with the largest thickness, the density of this wall is rather low $(-29.98 \pm 208.54 \mathrm{Hu})$. The low density of this area can probably lead to the spread of a purulentinflammatory process from the upper teeth to the maxillary sinus [17].

As can be seen from tables 1 and 2, bone thickness is a fairly constant indicator-less than the density changes under the influence of inflammatory changes in the sinus. Consequently, in assessing the degree of destructive changes in the sinus walls, perhaps we should rely more on density indicators [18].

In addition, both walls (both the lower and the posterior walls) respond to the inflammatory process by decreasing the density, and the decrease in density is most pronounced with the maximum degree of severity of the inflammatory process in the sinus, which is associated with the appearance of purulent-polypous frontal sinusitis. Thus, bone density depends on the severity of changes in the PNS in patients with different age and physical state $[19,20]$. SCT examination can help to determine not only the main morphological aspects of the bone structure, but also to measure its density. Maybe our study will help for the development of artificial intellect or other computed technologies [21-25] for the future studying of medical care workers or doctors [26] in different severity cases of pathological changes in paranasal sinuses or oral cavity [27-29], that allows accepting our results as useful in different field.

\section{Conclusions}

1. According to SCT, the minimum density and thickness of the lower and posterior walls of the frontal sinus and upper and lower walls of the maxillary sinus was established under physiological conditions. The density of the posterior wall was found to be $25.4 \%$ lower than the density of the lower wall, and the thickness $22.2 \%$ lower.

2. The wall thickness values were shown to be $1.0006 \pm 0.538 \mathrm{~mm}$ for the posterior wall of the frontal sinus and $4.47 \pm 2.11 \mathrm{~mm}$.

3. The posterior wall was the thinnest among all PNSs in all the studied groups. In addition, it had a minimum density, creating the conditions for the spread of purulent-inflammatory process in the skull.

4. The lower wall of the maxillary sinus is quite thick, but has a minimum density, which can create favorable conditions for the development of odontogenic maxillary sinus. 


\section{References}

1. Yazici D. (2019). The Analysis of Computed Tomography of Paranasal Sinuses in Nasal Septal Deviation. The Journal of craniofacial surgery, 30(2), e143-e147. https://doi.org/10.1097/ SCS.0000000000005077

2. Alekseeva V.V., Lupyr A.V., Urevich N.O., Nazaryan R.S., Gargin V.V. (2019). Significance of anatomical variations of maxillary sinus and ostiomeatal components complex in surgical treatment of sinusitis. J. Novosti Khirurgii, 27,168-176.

3. Nechyporenko A.S., Reshetnik V.M., Alekseeva V.V., Yurevych N.O., Nazaryan R.S., Gargin V.V. (2019). Assessment of Measurement Uncertainty of the Unicinated Process and Middle Nasal Concha in Spiral Computed Tomography Data, Problems of Incommunications Science and Technology (PIC S and T) Kyiv, Ukraine, 584-587.

4. Vogt K., Bachmann-Harildstad G., Lintermann A., Nechyporenko A., Peters F., Wernecke K.-D. (2018). The new agreement of the international RIGA consensus conference on nasal airway function tests. Rhinology, 56(2),133-143.

5. Stoll D. (2001). Inflammatory Acute Rhinosinusitis. Presse Med, 30(39-40 Pt 2), 33-40.

6. Sommer F., Hoffmann T.K., Harter L., D?scher J., Kleiner S., Lindemann J., Leunig A. (2019). Incidence of anatomical variations according to the International Frontal Sinus Anatomy Classification (IFAC) and their coincidence with radiological sings of opacification. Otorhinolaryngol, 276(11), 3139-3146.

7. Dong Y., Zhou B., Niu Y.T., Wang Z.C. (2011). CT evaluation of bone remodeling in rabbit models with rhinosinusitis. Chinese J. of Otorhinolaryngology Head and Neck Surgery, 46(10),848-853.

8. Georgalas C., Videler W., Freling N., Fokkens W. (2010). Global Osteitis Scoring Scale and chronic rhinosinusitis: a marker of revision surgery. Clin Otolaryngol,35(6),455-61. doi: 10.1111/j.17494486.2010.02218.x.

9. Lyndin M., Gluschenko N., Sikora V. et al. (2019) Morphofunctional features of articular cartilage structure. Folia Medica Cracoviensia, 59(3), 81-93.

10. Krivenko S, Demchenko D, Dyogtev I, Lukin V. A Two-Step Approach to Providing a Desired Quality of Lossy Compressed Images. Advances in Intelligent Systems and Computing 1113 AISC 2020: 482-491.

11. Krivenko S.S., Krivenko S.A. (2014). Many-to-many linear-feedback shift register. Electronics and Nanotechnology (ELNANO), IEEE 34th International Conference. Kyiv, Ukraine, 176-178.

12.Gach P., Tuchtan-Torrents L., Delteil C., Adalian P., Piercecchi M.D., Ebert L.C., Gorincour G. (2019) Virtual reconstruction of paranasal sinuses from CT data: A feasibility study for forensic application. Diagn Interv Imaging, 100(3), 163-168.

13. DenOtter T.D., Schubert J. (2019). Hounsfield Unit. In: StatPearls [Internet]. Treasure Island (FL): StatPearls Publishing; 2020 Jan.

14. Demiralp K.O., Kursun Cakmak S., Aksoy S., Bayrak S., Orhan K., Demir P. (2019). Assessment of paranasal sinus parameters according to ancient skulls' gender and age by using cone-beam computed tomography. Folia Morphol (Warsz), 344-350. doi: 10.5603/FM.a2018.0089. Epub 2018 Oct 3.

15. Lee Y., Choi H.G., Shin D.H., Uhm K.I., Kim S.H., Kim C.K., Jo D.I. (2014). Subbrow approach as a minimally invasive reduction technique in the management of frontal sinus fractures.Arch Plast Surg,41(6),679-85. doi: 10.5999/aps.2014.41.6.679. Epub 2014 Nov 3.

16. Szyfter W., Bartochowska A., Borucki ?., Maciejewski A., Kruk-Zagajewska A. (2018) Simultaneous treatment of intracranial complications of paranasal sinusitis. Eur Arch Otorhinolaryngol.,275(5),11651173. doi: 10.1007/s00405-018-4932-5. Epub 2018 Mar 13.

17. Nechyporenko A.S., Kryvenko S.S., Alekseeva V., Lupyr A., Yurevych N., Nazaryan R.S., Gargin V.V. (2019). Uncertainty of measurement results for anatomical structures of Pparanasal sinuses. Proc. 8th Mediterr. Conf. on Embedded Computing, Budva, Montenegro, 570-574.

18. Kuzenko Y., Romanyuk A., Korobchanskaya A., Karpenko L.(2014) Periodontal bone response under the influence of Cr(VI). Osteologicky Bulletin, 19(1):23-27.

19. Romanenko, V., Podrigalo, L., Iermakov, S., Rovnaya, O., Tolstoplet, E., Tropin, Y., \& Goloha, V. (2018). Functional state of martial arts athletes during implementation process of controlled activity comparative analysis. Physical Activity Review, 6, 87-93. doi:10.16926/par.2018.06.12

20. Gargin V.V., Alekseeva V.V, Lupyr A.V., Urevich N.O., Nazaryan R.S, Cheverda V.M. (2019). Correlation between the bone density of the maxillary sinus and body mass index in women during the menopause. J. Problemi Endokrinnoi Patologii, 2(68), 20-26. 
21.Chumachenko D., Chumachenko T. (2020) Intelligent agent-based simulation of HIV epidemic process. Advances in Intelligent Systems and Computing,1020,175-188. doi:10.1007/978-3-030-26474-1_13

22.Chumachenko D., Meniailov I., Bazilevych K., Chumachenko T.(2019). On intelligent decision making in multiagent systems in conditions of uncertainty. 11th International Scientific and Practical Conference on Electronics and Info rmation Technologies, ELIT 2019 - Proceedings, 150-153. doi:10.1109/ELIT.2019.8892307

23.Polyvianna Y., Chumachenko D., ChumachenkoT. (2019). Computer aided system of time series analysis methods for forecasting the epidemics outbreaks. $15^{\text {th }}$ International Conference on the Experience of Designing and Application of CAD Systems, CADSM 2019 - Proceedings, doi:10.1109/ CADSM.2019.8779344

24.Chumachenko D., Balitskii V., Chumachenko T., MakarovaV., Railian M. (2019). Intelligent expert system of knowledge examination of medical staff regarding infections associated with the provision of medical care. CEUR Workshop Proceedings, 2386, 321-330.

25. Gargin V., Radutny R., Titova G., Bibik D., Kirichenko A. Bazhenov O. (2020). Application of the computer vision system for evaluation of pathomorphological images. IEEE 40th International Conference on Electronics and Nanotechnology (ELNANO), Kyiv, Ukraine, 469-473, doi: 10.1109/ ELNANO50318.2020.9088898.

26.Chumachenko D., Meniailov I., Bazilevych K., Kuznetsova Y., Chumachenko T. (2019). Development of an intelligent agent-based model of the epidemic process of syphilis. IEEE 2019 14th International Scientific and Technical Conference on Computer Sciences and Information Technologies, CSIT 2019 - Proceedings, 1, 42-45. doi:10.1109/STC-CSIT.2019.8929749

27.Kovach, I., Kravchenko, L., Khotimska, Y., Nazaryan, R., \& Gargin, V. (2017). Influence of ozone therapy on oral tissue in modeling of chronic recurrent aphthous stomatitis. Georgian medical news, (264), 115-119.

28.Kovach, I., Buniatian, K., Makarevych, A., Verbyts'ka, A., \& Gargin, V. (2018). Influence of tricalcium silicate on course of traumatic pulpitis. Georgian medical news, (276), 130-134.

29.Denga, O., Pyndus, T., Gargin, V., \& Schneider, S. (2017). Influence of metabolic syndrome on condition of microcirculatory bed of oral cavity. Georgian medical news, (273), 99-104.

Received: 04-Aug-2020

Accepted: 12-Sep-2020 